\title{
Stapled trans-anal rectal resection (STARR) \\ for the surgical treatment of obstructed defecation syndrome associated with rectocele and rectal intussusception
}

\author{
Hesham M Hasan,a MD; Hani M Hasan,b MD
}

a) Department of General surgery, Ain Shams University, Cairo, Egypt.
b) Department of Obstetrics and Gynecology, AL-Azhar University, Cairo, Egypt. Abstract

Obstructed defecation syndrome (ODS) is one of the most widespread clinical problems which frequently affect middle - aged females. There is a new surgical technique called stapled trans-anal rectal resection, (STARR) which makes it possible to remove the anorectal mucosa circumferential and reinforce the anterior anorectal junction wall with the use of a circular stapler. This surgical technique developed by Antonio Longo, was proposed as an effective alternative for the treatment of ODS. In this study we present our preliminary results with the STARR operation for the treatment of ODS. For this purpose, 40 consecutive female patients with ODS due to rectal intussusception (RI) and/or rectocele (RE), were recruited in this prospective clinical study, from May 2008 to October 2010. No major operative or postoperative complications were recorded, and after 12-months follow-up, significant improvement in the ODS score system was observed. The symptoms of constipation improved in $90 \%$ of patients, $20 \%$ of patients judged their final clinical outcome as excellent, 55\% as good, $15 \%$ as moderate, with only $10 \%$ having poor results. After analyzing our results we can conclude that STARR is an effective and safe procedure for the treatment of obstructed defecation syndrome due to rectal intussusception and/or rectocele, and can be performed safely without major morbidity.

Key words: Obstructed defecation syndrome, stapled transanal rectal resection (STARR), rectocele, rectal intussusceptions.

\section{Introduction:}

Obstructed defecation syndrome (ODS) is a frequently occurring condition which usually affect middle - aged females. This disease can affect the quality of life of many patients, as these patients are obliged to spend several hours a day in the toilet; other symptoms of this disease include feeling of incomplete evacuation, excessive straining during defecation, the need for digital vaginal or perineal assistance and the use of enemas or suppositories to defecate. IThe etiology of ODS may be functional disorders, secondary to a spastic pelvic floor syndrome, in which failure to relax, or paradoxical contraction of the anal sphincters muscles can causes the symptoms of ODS or anatomical rectal anomalies as rectal intussusception (RI) and/or rectocele (RE).2 By using anal 3-dimensional ultrasonography (3-DAUS), Regadas et a1.,3 demonstrated that the anal canal is asymmetrical and that the internal anal sphincter is shorter in women, it is formed distally in the anterior upper anal canal weakening the anorectal junction which is devoid of striated muscle or any other anatomic support structure. ${ }^{4}$ Thus, herniation starts in the anterior upper anal canal and anorectal junction wall as demonstrated by echodefecography and anal 3-dimensional ultrasonography (3-DAUS) technique, suggesting that these patients have anorectocele rather than rectocele. 5

Conservative therapy is considered the first line of treatment inpatients with ODS as more than $30 \%$ of these patients showed an improvement with diet and biofeedback therapy. Also this line of management can avoid unnecessary and potentially dangerous surgery. Surgery should be reserved for patient with structural abnormalities who fail to respond to conservative treatment.6 Patients 
who do not respond to conservative treatment are usually multiparous females affected by a combination of intussusception and rectocele. In these patients the correction of rectocele with a vaginal or perineallevatorplasty is often ineffective.6,7

Stapled mucosectomy for treatment of rectal mucosa prolapse and hemorrhoids was initially described in 1997,8 and many publications have mentioned satisfactory results.9,10,11,12 Recently, a new technique named stapled transanal rectal resection; (STARR) developed by Antonio Longo has been described to treat the anorectal dysfunction such as rectocele and rectal intussusceptions.13,14 STARR involves a double stapling technique with the use of a circular stapler to remove the anorectal mucosa circumferential and reinforce the anterior anorectal junction wall correcting the structural abnormalities associated with ODS. Many publications demonstrated safety and efficacy of this procedure for the treatment of ODS and the published results reported symptomatic improvement among those patients_15,16

In this study we present our preliminary results with the STARR operation for the treatment of obstructive defecation syndrome due to RI and RE.

\section{Patients and methods:}

From May 2008 to October 2010, 40 consecutive female patients with ODS caused by $\mathrm{RE}$ and/or RI were recruited in this prospective clinical study which was performed at AL-Jedaani hospital and Ibn Sena Medical College, Jeddah, Saudi Arabia.

All patients gave their written informed consent before participating in this study.

\section{Inclusion criteria:}

-Patients with symptoms of obstructed defecation due structural abnormalities (rectocele and /or rectal intussusceptions) who failed to respond to conservative measures in the form of diet therapy, laxatives, enemas and/or physiotherapy for more than six months and at least a score of 12 on obstructed defecation syndrome score (ODS-S) Table(I).

-All the patients with an ODS-S 12 with RI (intussusceptions $10 \mathrm{~mm}$ ) and/or RE (extending 2 em or more from the rectal wall contour) shown by defecography Figure(l).
The presence of hemorrhoids was not a contraindication for inclusion in the study.

\section{Exclusion criteria:}

These included patients with good response to conservative treatment, slow transit constipation, severe fecal incontinence, enterocele (grade 3, 4, and 5), and complete rectal prolapse of more than $3 \mathrm{em}$. Also patients with cystocele were excluded.

Preoperative clinical evaluation included complete history of presenting symptoms, numbers of pregnancies, history of episiotomy, and previous pelvic or anal surgeries. Clinical examination of the perineum, rectum, and vagina was done to diagnose any associated diseases. Proctoscopy was performed for all patients to exclude any associated anorectal diseases.

Preoperative preparation included one or two enemas at the morning of surgery, routine deep vein thrombosis prophylaxis and perioperative broad spectrum antibiotics. General or spinal anaesthesia was used based on the individual anesthetist preference. Two circular PPH-01TM staplers (Ethicon EndoSurgery, Inc., USA) were used. The patient was placed in the lithotomy position. An initial examination was undertaken to confirm the presence and extent of the internal rectal prolapse and rectocele and also to confirm the absence of co-existent pathology Figure(2). Circular anal dilator was inserted into the anal canal and maintained secured to the perianal skin with two stay sutures (anterior and posterior). The rectocele was pushed through the anal canal with a finger inserted into the vagina to identify its apex; the posterior vaginal wall was pulled up with a Babcock forceps, the apex of the rectocele was pulled down Figure(3). Three semi-circumferential pursestring sutures were positioned in the anterior rectum at approximately 1,2, and 3 em above the haemorrhoidal apex. The first PPH-01TM stapler was inserted and the posterior rectal wall was protected with a spatula. The ends of sutures were delivered through the specific holes of the stapler, and tension was applied to prolapse the removed tissues into the stapler housing, making sure that the posterior vaginal wall had not been incorporated, the stapler was closed and fired. By the same procedure, two 
semi-circumferential purse-string sutures and a second $\mathrm{PPH}-01^{\mathrm{TM}}$ stapler were performed on the posterior rectal wall Figure(4), Figure(S). Hemostatic stitches with fullthickness 2-0 Vicryl ${ }^{\mathrm{TM}}$ stitches were used to control bleeding fromstaples line.All surgical specimens obtained from procedure were sent for histological examination.

All patients had detaileddata on preoperative status, perioperative and postoperative complications. A clinical assessment was performed at baseline and at 3, 6, and 12 months after surgery. The magnitude and degree of ODS were quantifiedby constipation scoring system (CSS)_17 The validated CSS consists of five items and the overall score ranges from 0 (normal) to 20 (severe constipation). The index of patient satisfaction was evaluated by a visual analog scale (VAS: with a score from 0 to 10 ), and a higher score suggests an improvement inpatient satisfaction after the surgery.

Statistical analysis was performed using paired $t$ test for continuous variables, and Wilcoxon's signed-rank test for quantitative variables. A $\mathrm{P}$ value $<0.05$ was considered statistically significant.

Table (1): Obstructed defecation syndrome score.

\begin{tabular}{|l|c|c|c|c|c|}
\hline \multicolumn{1}{|c|}{ symptoms } & Never & Rarely & Sometimes & usually & Always \\
\hline Excessive straining & 0 & 1 & 2 & 3 & 4 \\
\hline Incomplete rectal evacuation & 0 & 1 & 2 & 3 & 4 \\
\hline UseofenenuuVlaxative & 0 & 1 & 2 & 3 & 4 \\
\hline Vaginal/perineal digital pressure & 0 & 1 & 2 & 3 & 4 \\
\hline Constipation & 0 & 1 & 2 & 3 & 4 \\
\hline
\end{tabular}

Never: 0 (never); rarely: <]/month, Sometimes: <]/week, ?::\}/month;

Usually: <1/day, ?::1/week; Always: ?::1/day

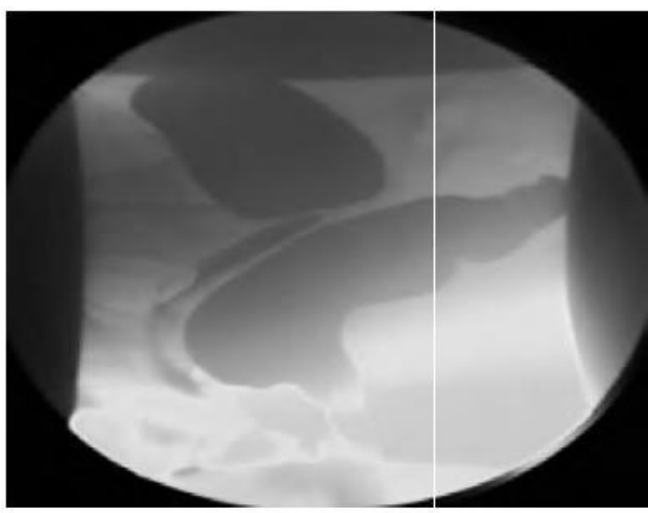

Figure (1): Cystocolpodefecography in sitting position during straining; the posterior colpocele is caused by a significant rectocoele.

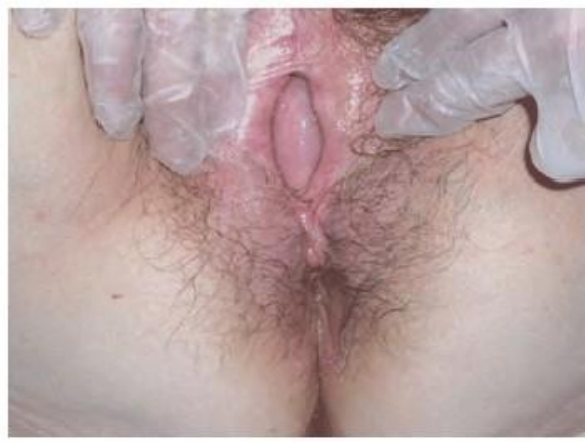

Figure (2): Anterior rectocele.

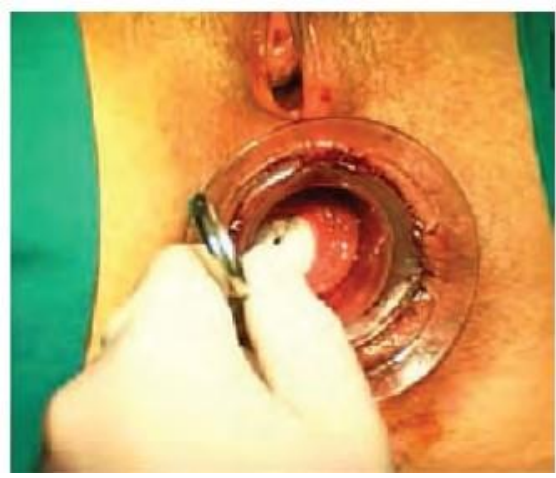

Figure (3): Apex of the rectocele was pulled down. 


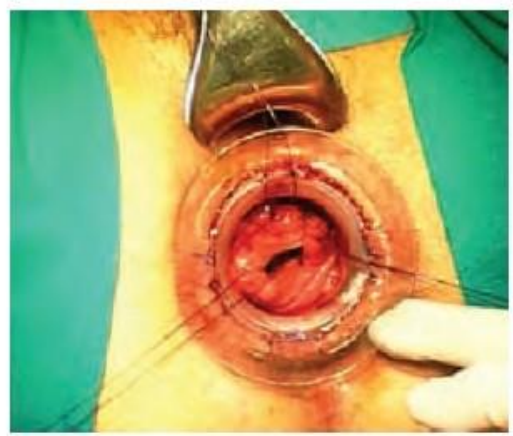

Figure (4): Three semi-circumferential purse-string sutures.

\section{Results:}

During the period between May 2008 to October 2010 there were 40 female patients with ODS caused by RE and/or RI (median age, 45.7 \pm 12.3 years; range, 30-63 years) subjected to trans-anal rectal resection using PPH-01TM staplers (Ethicon EndoSurgery,Inc.,USA) were included in this prospective study. All had been followed up for 12 months after surgery.

An anterior rectocele was present in 36 patients (90\%) and 22 patients (55\%) bad an internal rectal prolapse and/or rectal mucosal prolapse. 32 patients $(80 \%)$ had experienced 1-6 vaginal deliveries, 12 patients $(30 \%)$ had experienced at least one episiotomy, and 18 patients $(45 \%)$ bad undergone prior anorectal or gynecologic surgeries. All patients had symptoms of obstructed defecation syndrome Table(2).

The median operative time was $35 \pm 10$ minutes, and the median hospital stay was $1.7 \pm 2.3$ (ranging from 1 to 5 ) days, the specimen dimensions were $6.8 \pm 2.5 \times 9.7 \pm 1.9$ em (height $\mathrm{x}$ width); rectal smooth muscle fibers were found in all the specimens. The only intraoperative complication was bleeding from the anastomotic ring, which occurred in $800 \%$ of cases and was secured with hemostatic stitches. The most common morbidity after surgery was defecatory urgency, and the incidence was $40 \%$ during the first postoperative week and decrease to $10 \%$ after

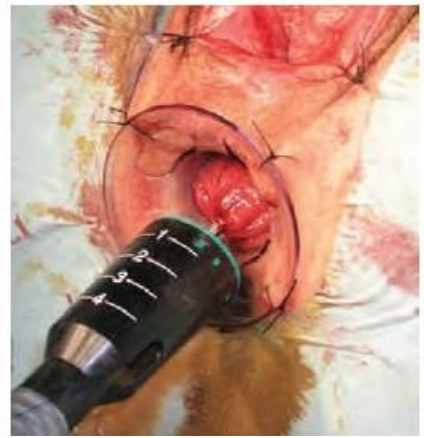

Figure (5): $P$ PH-01 ${ }^{\mathrm{TM}}$ stapler.

threemonths follow up.Post operative bleeding occurred in $4(10 \%)$ patients, but it was minor and stopped spontaneously with conservative trealment with no further surgical intervention required. Other recorded complications were incontinence to flatus in $2(5 \%)$ patients, acute urinary retention in $2(5 \%)$ patients, persistent post operative pain in $4(10 \%)$ patients and anal fissure in one $(2.5 \%)$ patient. No staple line dehiscence, massive rectal hemorrhage, rectovaginal fistula and perianal sepsis occurred, also, there were no postoperative mortality recorded Table(3). At 12 months follow-up, the symptoms of constipation improved in 36 (90\%) patients however, constipation persists or recurred in 4 patients after STARR procedure. There were a significant reduction in ODS scores at 12 months follow up as compared with baseline Table $(4,5)$.

Postoperative cinedefecography showed residual anorectoceles (grade $\mathbf{1 - U}$ ) in 6 (15\%) patients and residual second degree rectocele with internal mucosal prolapsed in $3(7.5 \%)$ patients. As compared to preoperative defecographic findings, anterior rectocele was significantly reduced from $90 \%$ to $15 \%$ of patients $(\mathrm{P}<0.001)$.

After 12 months follow up eight patients (20\%) judged their final clinical outcome as excellent, 22 patients (55\%) as good, 6 patients $(15 \%)$ as moderate, with only four patients (10\%) having poor results $\operatorname{Table(6).~}$ 
Table (2): Presenting symptoms.

\begin{tabular}{|l|c|}
\hline \multicolumn{1}{|c|}{ Symptoms } & Incidence \\
\hline Excessive straining & $32(80 \%)$ \\
\hline Feeling of incomplete evacuation & $28(70 \%)$ \\
\hline Abdominal distension & $22(55 \%)$ \\
\hline Feeling of rectal obstruction & $14(35 \%)$ \\
\hline Rectal or vaginal digitation & $12(30 \%)$ \\
\hline Laxatives more than 2 times/week & $26(65 \%)$ \\
\hline Enema more than once/month & $10(25 \%)$ \\
\hline
\end{tabular}

Table (3): Postoperative complications.

\begin{tabular}{|l|c|c|c|c|}
\hline \multicolumn{1}{|c|}{ Symptoms } & First week & After3 mo & After 6 mo & After 12 mo \\
\hline Defecatory urgency & $16(40 \%)$ & $4(10 \%)$ & $2(5 \%)$ & $1(2.5 \%)$ \\
\hline Post operative bleeding & $4(10 \%)$ & 0 & 0 & 0 \\
\hline Acute urinary retention & $2(5 \%)$ & 0 & 0 & 0 \\
\hline Incontinence to flatus & $2(5 \%)$ & 0 & 0 & 0 \\
\hline Pain & $4(10 \%)$ & $2(5 \%)$ & $1(2.5 \%)$ & 0 \\
\hline Anal fissure & $1(2.5 \%)$ & $1(2.5 \%)$ & $1(2.5 \%)$ & $1(2.5 \%)$ \\
\hline
\end{tabular}

Table (4): Preoperative obstructed defecation syndrome score of the 40 patients.

\begin{tabular}{|c|c|}
\hline Obstructed defecation score & No. of Patients (\%) \\
\hline $12-14$ & $8(20 \%)$ \\
\hline $15-17$ & $26(65 \%)$ \\
\hline $18-20$ & $6(15 \%)$ \\
\hline
\end{tabular}

Tabk (5): The obstructed defecation syndrome score before and at 12 months after the stllpling procedure.

\begin{tabular}{|l|c|c|c|c|}
\hline \multicolumn{1}{|c|}{ ODS symptoms } & $\begin{array}{c}\text { Preoperative, } \\
\text { mean(SD) }\end{array}$ & $\begin{array}{c}12 \text { months, } \\
\text { mean (SD) }\end{array}$ & T test & Pvalue \\
\hline constipation & $3.8(2.04)$ & $0.6(0.42)$ & 9.72 & $<0.001$ \\
\hline Excessive straining & $2.8(0.92)$ & $0.4(0.32)$ & 15.58 & $<0.001$ \\
\hline Incomplete rectal evacuation & $2.5(1.06)$ & $0.6(0.86)$ & 8.80 & $<0.001$ \\
\hline Use of Laxatives/ enemas & $3.3(2.14)$ & $0.7(1.15)$ & 6.77 & $<0.001$ \\
\hline VaginaVperineal digital pressure & $1.8(1.88)$ & $0.0(0.00)$ & 6.06 & $<0.001$ \\
\hline Total score & $14.2(9.13)$ & $2.3(2.9)$ & 7.87 & $<0.001$ \\
\hline
\end{tabular}

$P<0.001=$ highly significant . 
Table (6): Subjective evaluation of outcome after surgery at six months foUow-up.

\begin{tabular}{|c|c|c|}
\hline Subjective evaluation of outcome & No. of patients & $\%$ \\
\hline Excellent & 8 & $20 \%$ \\
\hline Good & 22 & $55 \%$ \\
\hline Moderate & 6 & $15 \%$ \\
\hline Poor & 4 & $10 \%$ \\
\hline
\end{tabular}

\section{Discussion:}

ODS is a challenging clinical problemthe pathophysiology of which remains not clearly defined RE and RIhoweverare the two most frequent anatomic defects associated with ODS. Although various surgical procedures have been described for the treatment of the syndromemany of these are unsuitable for patients accompanied with RE and RI.ls Until the development of the STARR technique there was no surgical procedure for correction of ODSand patients were treated conservatively with diet and biofeedback therapy. In contrast to the transvaginal approach and perineal levatorplasty used to treat rectocele, the STARR procedure corrects both rectocele and rectal intussusception.19 Traditional operations in patients with both rectal mucosal prolapse and rectocele are associated with a high incidence of delayed healing of the perineal wound and dyspareunia. The combined endo-anal and perineal approach increased the risk of sepsis due to fecal contamination and led to potentially fatal cases of pelvic gangrene. 19

STARR has been demonstrated as an alternative operation and a relatively non invasive surgical technique for ODS caused by RE and RI. The novel procedure aims to correct rectocele, resect internal prolapse, restore anatomy, correct rectal volume, and improve function.20 But it has been demonstrated that patient selection should be very careful because only symptomatic rectocele or rectal intussusception\& justifies surgical treatmenother associated pathologies such as irritable colon or pudendal neuropathy are not modified by operation so symptoms may persist.21 A multicentric study done by Stuto et ai.,22 demonstrated that STARR procedure, for management of ODS, is technically simple to perform and able to revert all constipation symptoms; the operative time and hospital stay were shortthe postoperative pain and bleeding were minimalthere were no sepsis or postoperative dyspareuniaand patients return early to work. Several studies confirm the safety and efficacy of the STARR procedure for management ofODS.23-25 Also the data collected from this prospective clinical study suggest thatmore than $90 \%$ of our patients had satisfactory surgical results with improved symptoms of ODS with STARR procedure, coupled with few intraoperative and postoperative complications. The only intraoperative incident was bleeding from the staple line which occurred in $80 \%$ of patients so the anastomotic ring should be meticulously checked and carefully secured with stitches whenever necessary. The most common morbidity after surgery was defecatmy urgency and the incidence inour study was $40 \%$ during the first postoperative week and decreased to $10 \%$ after three months follow up. Other published studies have shown that defecatory urgency was the most common complaint in the immediate and intermediate recovery periods after STARR25,26 Although the exact etiology of defecatory urgency is unclearit may reflect the inflammatory response related to the staple line, presence of irritable rectum and reduced rectal capacity or compliance. No major complications such as massive rectal hemorrhage and anastomotic line dehiscence occurred in our study. Few studies reported the incidence of severe complications such as staple line dehiscencerectal diverticulum pelvic infection and even fulminating necrotizing pelvic fasciitis following the STARR procedure.27,28 Incontinence has been claimed to be a potential postoperative drawback of STARR, it may be a procedurerelated complication caused by transient sphincteric impairment during instrumentation and anal dilatation.29-31 In this studyonly two 
(5\%) patients complained of incontinence to flatus during the first two weeks after the procedures and improved within 3 months of surgery. Our results confirmed that the rate of postoperative pain was low, and there were no cases of dyspareunia. Also, Edward et al.,32 in their prospective study concluded that, STARR procedure is safe and effective, particularly in young females, due to the absence of complications related to the perineal levatorplasty and better results on postoperative pain, absence of dyspareunia and better clinical outcome. Frascio et aP3 in their trial on 30 patients reported no mortality or pelvic sepsis and $4 \%$ of post operative bleeding treated surgically, while in our study Postoperative bleeding occurred in $4(10 \%)$ patients, but it was minor and stopped spontaneously with conservative treatment with no further surgical intervention required.

It is reasonable to suggest that the high percentage of successful results obtained, the short postoperative length of stay and the short time to return to work after STARR procedure for management of ODS would balance the relatively high cost of the procedure.

\section{Conclusion:}

Obstructed defecation syndrome (ODS) is one of the most widespread clinical problems which frequently affect middle-aged females. Rectocoele (RE) and rectal intussusception (RI) are the two most common anatomic defects associated with ODS. STARR represents a true revolution in the surgical treatment of ODS caused by (RE) and/or (RI) and it appeared to be safe and effective with a successful outcome in most of the patients. Longer follow up period more than 12 months may be needed to assess long term functional outcomes and symptomatic recurrence.

\section{References:}

1- Kamm MA: Constipation. In: Surgery of the colon \& rectum. Nicholls RJ, Dozois RR (Editors); Churchill Livingstone, New York (Publisher); 1997; p. 657-669.

2- Keighley MRB, Stipsi. In: Chirurgia di ano-retto e colon. Keighley MRB, Williams NS (Editors); Piccin, Padova (Publisher); 2000; p. 615-644.
3- Regadas SM, Regadas FS, Rodrigues LV, Silva FR, Lima DM, Regadas-Filho FS: Import,ncia do ultra-som tridimensional na avali ao anorretal. Arq Gastroenterol 2005; 42: 226-232.

4- Fritsch H, Hotzinger H: Tomographical anatomy of the pelvis, visceral pelvic connective tissue and its compartments. Clin Anat 1995; 8: 17-24.

5- Regadas FS, Regadas SM; Rodrigues LV, Misici R, Tramujas I, Barreto JB, Lins MA, Silva FR, Filho FS: New devices for stapled rectal mucosectomy: A multicenter experience. Tech Coloprocto/2005; 9: 243246.

6- Singh K, Cortes E, Reid WM: Evaluation of the fascial technique for surgical repair of isolated posterior vaginal wall prolapse. Obstet Gynecol 2003; 101: 320-324.

7- Watson SJ, Loder PB, Halligan S, Bartram CL, Kamm MA, Phillips RK:Transperineal repair of symptomatic rectocele with Marlex mesh: A clinical, physiological and radiological assessment of treatment. JAm Coli Surg 1996; 183: 257-261.

8- Pescatori M, Favetta V, Dedola S, Orsini S: Stapled transanal excision of rectal mucosa prolapses. Tech Coloprocto/1997; 1: 96-98.

9- Habr-Gama A, Sousa AH Jr, Rovel6 JM, Souza JV, Benicio F, Regadas FS, Wainstein C, da Cunha TM, Marques CF, Bonardi R, Ramos JR, Pandini LC, Kiss D: Stapled hemorrhoidectomy: Initial experience of a Latin American group. $J$ Gastrointestinal Surg 2003; 7: 809-813.

10-Nahas SC, Borba MR, Brochado MC, Marques CF, Nahas CS, Miott-Neto B: Stapled hemorrhoidectomy for the treatment of hemorrhoids. Arq Gastroentero/2003; 40:35-39.

11-Sobrado CW, Cotti GC, Coelho FF, Rocha JR: Initial experience with stapled hemorrhoidopexy for treatment of hemorrhoids. Arq Gastroentero/2006; 43: 238-242.

12-Wilson MS, Pope V, Doran HE, Fearn SJ, Brough WA: Objective comparison of stapled anopexy and open hemorrhoidectomy: A randomized, controlled trial. Dis Colon Rectum 2002; 45: 1437-1444. 
13-Longo A: Treatment of hemorrhoidal disease by reduction of mucosa and hemorrhoidal prolapse with a circular suturing device: A new procedure. In: Proceedings of the 6th World Congress of Endoscopic Surgery. Bologna Italy Monduzzi Editore 1998; 777-784.

14-Altomare DF, Rinaldi M, Veglia A, Petrolino M, De Fazio M, Sallustio P: Combined perineal and endorectal repair of rectocele by circular stapler: A novel surgical technique. Dis Colon Rectum 2002; 45: 1549-1552.

15-Ayav A, Bresler L, Brunaud L, Boissel P: Long-term results of transanal repair of rectocele using linear stapler. Dis Colon Rectum 2004; 47: 889-894.

16-Renzi A, Izzo D, Di Sarno G, lzzo G, Di Martino N: Stapled transanal rectal resection to treat obstructed defecation caused by rectal intussusception and rectocele. Int J Colorectal Dis 2006; 21 : 661-667.

17-Agachan F, Chen T, Pfeifer J, Reissman P, Wexner SD: A constipation scoring system to simplify evaluation and management of constipated patients. Dis Colon Rectum 1996; 39: 681-685.

18-Boccasanta P, Venturi M, Calabro G, Trompetto M, Ganio E, Tessera G, Bottini C, Pulvirenti D'Urso A, Ayabaca S, Pescatori M: Which surgical approach for rectocele? A multicentric report from Italian coloproctologists. Tech Coloproctol2001; 5: 149-156.

19-Boccasanta P, Venturi M, Calabro G, et al: Which surgical approach for rectocele? A multicentric report from Italian coloproctologists. Tech Coloproct 2001; 5: 147-154.

20-Boccasanta P, Venturi M, Stuto A, Bottini C, Caviglia A, Carriero A, Mascagni D, Mauri R, Sofo L, Landolfi V: Stapled transanal rectal resection for outlet obstruction: A prospective, multicenter trial. Dis Colon Rectum 2004; 47: 12851296; discussion 1296-1297.

21-Van Dam JH, Hop WC, Schouten WR: Analysis of patients with poor outcome of rectocele repair. Dis colon rectum 2000; 43(11): 1556-1560.
22-Stuto A, Boccasanta P, Venturi M, et al: Stapled transanal rectal resection (STARR) for obstructed defecation. A prospective multicentric trial. AnnualMeeting Abstracts of American Society of Colon and Rectal Surgeons. Dis Colon Rectum 2000; 43: A21.

23-Reboa G, Gipponi M, Logorio M, Marino P, Lantieri F: The impact of stapled transanal rectal resection on anorectal function in patients with obstructed defecation syndrome. Dis Colon Rectum 2009;52: 1598-1604.

24-Arroyo A, GonzAlez-Argenre FX, GarciaDomingo M, Espin-Basany E, De-laPortilla F, Perez-Vicente F, Calpena R: Prospective multicentre clinical trial of stapled transanal rectal resection for obstructive defaecation syndrome. $\mathrm{Br} J$ Surg 2008; 95: 1521-1527.

25-Jayne DG, Schwandner O, Stuto A: Stapled transanal rectal resection for obstructed defecation syndrome: One-year results of the European STARR Registry. Dis Colon Rectum 2009; 52: 1205-1212; discussion 1212-1214.

26-Titu LV, Riyad K, Carter H, Dixon AR: Stapled transanal rectal resection for obstructed defecation: A cautionary tale. Dis Colon Rectum 2009; 52: 1716-1722.

27-Dodi G, Pietroletti R, Milito G, Binda G, Pescatori M: Bleeding, incontinence, pain and constipation after STARR transanal double stapling rectotomy for obstructed defecation.Tech Coloproctol2003; 7:148153.

28-Pescatori M, Zbar AP: Re-interventions after complicated or failed STARR procedure. Int J Colorectal Dis 2009; 24: 87-95.

29-Gagliardi G, Pescatori M, Altomare DF, et al: Results, outcome predictors, and complications after stapled transanal rectal resection for obstructed defecation. Dis Colon Rectum 2008; 51: 186-195.

30-Binda GA, Pescatori M, Romano G: The dark side of double-stapled transanal rectal resection. Dis Colon Rectum 2005; 48: 1830-1831.

31-Corman ML, Carriero A, Hager T, et al: Consensus conference on the stapled 
transanal rectal resection (STARR) for disordered defaecation. Colorectal Dis 2006; 8:98-101.

32-Ram E, Alper D, Atar E, Tsitman I, Dreznik $\mathrm{Z}$ : Stapled transanal rectal resection: A new surgical treatment for obstructed defecation syndrome. IMAJ 2010; 12: 74-78. 33-Frascio M, Stabilini C, et al: Stapled transanal rectal resection for outlet obstruction syndrome: Results and follow up. World J Surg 2008; 32(6):1110-1115. 